\title{
The Effect of Types of Respiratory Exercise on Respiratory Muscle Activity and Health-Related Quality of Life of Patients with Severe Chronic Obstructive Pulmonary Disease
}

\author{
Jeong-II Kang ${ }^{1}$, Dae-Keun Jeong ${ }^{1}$, Hyun Choi $^{2}$ \\ 'Department of Physical Therapy, Sehan University, Yeongam-gun, Jeollanam-do; ${ }^{2}$ Department of Physical Therapy, Mokpo Mirae Hosipital, Mokpo, \\ Korea
}

Purpose: This study intended to classify voluntary respiratory exercise and exercise using breathing training equipment to suggest proper respiratory exercise to relieve symptoms of patients with severe chronic obstructive pulmonary disease.

Methods: Sixteen subjects were randomly selected for experimental group I, which performed feedback breathing exercise and 15 subjects were randomly selected for experimental group II, which performed a complex breathing exercise. The mediation program was performed 30 minutes a session, once a day, three times a week, for five weeks. This study analyzed before and after results within groups and between groups through measurement of respiratory muscle activity and health-related quality of life.

Results: Activity of sternocleidomastoid muscle and scalene muscle increased meaningfully within experimental group I and activity of diaphragm increased significantly within experimental group II $(p<0.05)$ and there was a meaningful difference in health-related quality of life within experimental group II $(p<0.05)$. Significant differences in change of activity of respiratory muscle and health-related quality of life were observed between groups $(p<0.05)$.

Conclusion: This study showed conflicting results between activity of agonist and synergist in patients with severe chronic obstructive pulmonary disease according to types of respiratory exercise and that complex respiratory exercise is more effective in health-related quality of life. Therefore, it found that the more severity increase, the more self-respiratory technique is an effective program. Diversified approach methods will be needed to improve respiratory function and quality of life for patients, and continuous clinical studies will be needed in the future.

Keywords: Chronic obstructive pulmonary disease, Respiratory muscle activity, Quality of life

서 론

만성폐쇄성폐질환(Chronic Obstructive Pulmonary Disease, COPD) 은 세계보건기구(World Health Organization, WHO)가 2030년 사망원 인 3위로 예측하여 심각한 질환으로 대두되고 있으며, ${ }^{1}$ 세계적으로 노인 인구의 증가와 공해의 심각화로 인해 주목 받고 있는 질환이다. 또한 해를 거듭할수록 발병률과 사망률이 증가하는 추세이므로 현 재 만성폐쇄성폐질환을 포함한 호흡기 질환을 관리하는 것은 매우 중요함을 시사한다. ${ }^{2}$

만성폐쇄성폐질환 환자들의 이상요소들은 크게 가슴우리(thoracic cage)의 비정상적인 팽창으로 인한 호흡률의 제한과 가로막(diaphragm)의 모양이 평편해지는 변화가 일어나며, 이러한 제약은 기도
폐쇄와 더불어 호흡곤란 증상을 더욱 심하게 호소하는 요소로 작용 한다. ${ }^{3}$ 특히 가로막의 역학적 불이익이나 기류제한은 호흡패턴과 가 슴움직임의 변화에 원인이 되고, 호흡을 수행할 때 호흡근의 근력 유 지와 지구력을 높이기 위해 가슴 벽과 가로막의 모양이 근 섬유의 용 량 증가 및 적응을 수용하기 위해 변화하며, ${ }^{4}$ 그 결과 체력은 물론 운 동량 감소로 인해 근육량의 변화 등을 유발하게 되고 호흡근에도 영 향을 미치는 요소가 된다. ${ }^{5}$ 만성폐쇄성폐질환 환자는 호흡 시 호흡을 위한 노력이 증가함에도 불구하고 호흡량은 줄어들게 되는데, 이러 한 현상은 호흡근에 의하여 공급되는 에너지의 비율과 환자들의 호 흡성 수요가 일치되지 않기 때문이다. ${ }^{6}$ 그리고 질환이 악화될수록 호 흡 협력근들의 과다한 사용에 따라 환기성 기전의 변형들로 인해 호 흡성 부전이 나타나며, 다른 신체기능에도 악영향을 미치게 되며, ${ }^{7}$ 이
Received Jan 13, 2016 Revised Feb 17, 2016

Accepted Feb 22, 2016

Corresponding author Dae-Keun Jeong

E-mail dklovept@naver.com
Copylight (C) 2016 The Korea Society of Physical Therapy

This is an Open Access article distribute under the terms of the Creative Commons Attribution Non-commercial License (Http:// creativecommons.org/license/by-nc/3.o.) which permits unrestricted non-commercial use, distribution, and reproduction in any medium, provided the original work is properly cited. 
러한 악영향의 요소는 점진적으로 폐기능 손상을 야기하고 활동의 제한과 기능상실을 겪게 됨에 따라 삶의 만족에도 부정적인 영향을 미치게 된다. ${ }^{8}$ 따라서 증상을 완화하고 예방하기 위하여 신체 활동 능력 개선 등과 같은 효과적 질환의 관리가 중요하며, 특히 최근 환자 들의 기능적인 신체 기능의 향상이 치료의 목표로서 강조되고 있는 추세로써, ${ }^{9}$ 만성폐쇄성폐질환 환자의 삶의 질에 영향을 미칠 수 있는 요인에 관한 연구들이 많은 관심으로 제시되고 있다. ${ }^{8}$

만성폐쇄성폐질환이 장시간 지속되면 호흡기뿐만 아니라 신체 내 다양한 손상을 유발하여 환자의 전반적인 생활패턴과 정상적인 신 체 기능에 악영향을 미친다..$^{10}$ 이러한 요소들을 제어하기 위해 호흡 운동은 필수적인 요소로 중재방법은 크게 자발적인 호흡운동과 호 흡훈련 장비를 이용한 운동으로 분류되며, 가로막호흡운동과 오므 린 입술호흡운동의 결합된 자발적 호흡운동은 호흡률 개선에 효율 적인 것으로 나타났다." 그리고 폐활량 기구를 이용한 호흡운동방법 으로는 가로막과 들숨협력근에 부하를 적용함으로써 근육들의 근 력과 지구력 향상에 도움을 주는 방법으로 연구되어지고 있으나, ${ }^{2}$ 폐기능의 증상의 정도를 고려하여 운동수행에 대한 효과를 분석한 연구 또한 필요한 시점이다.

따라서 본 연구는 증상을 완화시키는 적합한 호흡운동을 제시하 기 위해 호흡훈련장비를 이용한 운동과 자발적인 호흡운동으로 분 류하여 폐기능이 악화된 중증폐쇄성폐질환 환자들의 호흡근들의 특성을 분석하고, 이를 바탕으로 일상생활의 기능과 활동을 개선하 여 건강관련 삶의 질을 향상시킬 수 있는 효율적인 중재방법을 알아 보고자한다.

\section{연구방법}

\section{1. 연구대상}

연구 대상자는 2014년 4월부터 2015년 1월까지 전라남도에 소재한 한 국병원에서 치료 중인 55-70세 연령범위의 남성 만성폐쇄성폐질환 환 자 31 명으로, 만성폐쇄성폐질환의 등급을 분류하는 GOLD stage 범위 가 중증인 대상자 중, 주요 내과적 질환(허혈성 심장질환, 간헐성 파 행증, 본 프로그램을 이행하기 불가능하다고 판단되는 합병증)을 병 합하지 않은 자, 선천적인 가슴우리의 변형이나 늑골의 골절 등의 동 반손상이 없는 자, 급진적 만성폐쇄성폐질환 증상이 없는 자로 본 연 구의 목적을 이해하고 연구에 참여하기로 동의한 자를 대상으로 하 였다.

\section{2. 실험방법}

1) 연구설계

피드백호흡운동을 중재한 실험군 16 명을 실험군 I로, 복합호흡운동
을 중재한 실험군 15 명을 실험군 II로 무작위 선정하였다. 사전검사로 는 표면 근전도로 호흡근활성도를 측정하였고 건강관련 삶의 질을 측정하기 위해 SGRQ으로 측정한 후, 5 주간, 주 3 회, 1 일 1회, 1 회 30 분 간 중재프로그램을 중재한 후, 사전검사와 동일하게 사후검사를 시 행하여, 집단 내 전후 비교와 집단 간 비교를 통해 분석하였다.

\section{2) 측정도구}

본 연구에 사용된 측정 도구로는 신장과 체중은 Body Mass Index HW-600 (Korea)을 사용하였고, 폐기능은 Chestgraph HI-701 (Chest, Japan)을 이용하여 FEV1, FEV1/FVC 를 측정하였다. 그리고 근활성도 는 MP 100 system (Biopac, USA)으로 근육들의 \%RVC를 측정하였으 며, 건강관련 삶의 질을 측정하기 위해 세인트 호흡기 설문지(St. Goerge's Respiratory Questionnaire, SGRQ)로 측정하였다.

\section{(1) 폐기능 측정}

폐기능 측정은 Chestgraph HI-701 (Chest, Japan)을 이용하여 측정하였 으며, 폐기능은 대상자에게 앉은 자세에서 호흡기계를 입에 물고 최 대한 숨을 들이 쉰 후, 힘껏 내뱉게 하여 측정된 수치를 기록하여 측 정하였다. 폐활량 측정은 최소 3 회 이상 실시하였고 검사치 중에서 가장 큰 수치와 그 다음 큰 수치 사이의 차이가 $5 \%$ 이내 또는 $200 \mathrm{~mL}$ 이내인수치를 측정 하였다.13

\section{(2) 호흡근 활성도 측정}

호흡보조근의 근활성도 측정은 표면 근전도 MP 100 system (Biopac, USA) 3 채널을 사용하였으며, 근전도 신호 수집을 위한 표본 추출률 (sampling rate)은 1,000으로 하였고, 주파수 대역 필터는 20-450 Hz로 설정하였다. 근전도 신호의 피부저항을 최소화하기 위해 대상자들의 피부에서 털을 제거하고 가는 사포를 이용하여 각질을 제거한 뒤 알 코올 솜으로 문질러 피부를 청결히 유지하였다. 2 개의 $\mathrm{Ag} / \mathrm{Agcl}$ 표면 전극을 사용하여 각 근육의 근복에 근섬유와 평행한 방향으로 $2 \mathrm{~cm}$ 간격으로 부착하였다. 기준 전극은 돌출된 부위인 어깨뼈 가시와 12 번째 등뼈의 가시돌기에 부착하였다. 측정 근육은 오른쪽 목빗근, 목 갈비근, 그리고 가로막의 근복에서 근전도 신호를 수집하였다.

측정 근육들의 신호들은 실효치 진폭(root mean square, RMS)으로 변환하였으며, 근전도 신호 분석은 Acqknowledge 3.9 .1 software program (Biopac, USA)을 사용하였다. 또한 대상자들의 근전도 신호를 정규화(normalizing)하기 위해 먼저 환자들을 편안하게 앉은 자세를 취하게 한 후 들숨호흡운동기구인 Threshold Inspiratory Muscle Trainer (New Jersey, USA)을 이용하여 최대 들숨압의 $30 \%$ 의 수준으 로 호흡을 10 회 시행하여 시작과 끝 2 회를 제외한 8 회 호흡 시 실효치 진폭값으로 $\% \mathrm{RMS}$ 값을 정량화하였다. ${ }^{14}$ 
(3) 건강관련 삶의 질 측정

SGRQ는 만성폐쇄성폐질환 환자의 건강관련 삶의 질을 측정하기 위 해 고안된 자가보고 도구이며 총 50 문항의 3 가지 영역으로 이루어져 있는데, 지난 한달 동안의 호흡기 증상의 빈도와 중증도를 반영하는 증상(symptom) 8 문항, 호흡곤란을 유발하거나 호흡곤란에 의해 제 한받는 활동 정도를 반영하는 활동력(activity) 16 문항, 사회적 기능, 정서적 기능에 대한 질병의 영향, 전반적인 장애 정도를 측정하는 영 향력(impact) 26 문항으로 구성되어 있고, 영역별 점수와 총 점수를 각 각 계산하여 0 에서 100 까지 점수로 표시되는데 점수가 낮을수록 호 흡기 증상과 관련된 삶의 질은 좋으며 점수가 높을수록 삶의 질은 떨 어진다. 측정은 $1: 1$ 직접 면담으로 시행하였으며 피검자가 직접 문항 을 읽고 표기하는 것을 원칙으로 하였고, 피검자가 시력, 청력적 문제 로 직접 표기하기가 불가능할 경우 검사자가 피검자에게 각 문항을 읽어 주고 자신의 상태를 가장 잘 나타내는 항목을 고르도록 하여 검사자가 기록하였다. ${ }^{8}$

\section{3. 중재방법}

\section{1) 피드백호흡운동}

피드백호흡운동의 운동방법은 SPIROTIGER ${ }^{\circledR}$ (Idiag AG, Switzerland)를 사용하였다. 중재방법은 환자가 몸통을 펴고 앉은 상태에서 마우스피스를 입에 물고 호흡주머니가 결합된 손잡이를 잡고, 눈으 로는 연결장치를 주시한다. 치료사가 연결장치의 시작 버튼을 누르면 환자는 눈으로 본체의 주황색 눈금이 “in" 이라는 표시 쪽으로 향하 면 들숨을 시행하고, "out" 이라는 표시쪽으로 향하면 날숨을 시행한 다. "in” 또는 "out” 쪽으로 주황색 표시등이 표시될 때 녹색불이 들어 오면서 삐-이 라는 소리가 들려올 때 정상적인 피드백호흡운동이 된 다. 환자의 이해를 돋기 위해 운동 전 충분한 설명을 제공하였다. 최대 들숨과 날숨 운동을 하는 동안 저이산화탄혈증(hypocarbia)이 일어
나지 않는 범위에서 시행하였다(Figure 1). 피드백호흡운동은 총 30 분, 준비운동 2분, 분당 26-27회 호흡(26-27 breaths/min)을 시행하고 2 분의 휴식시간을 제공하였다..$^{15}$

\section{2) 복합호흡운동}

치료사는 호흡운동을 실시하기 위해 환자를 바로 누워서 편안한 자 세로 준비시키고 들숨성 가로막 호흡운동이 끝나면 곧바로 날숨성 입술 오므리기 호흡운동을 시행하였다. 총 30 분, 4 session으로 구성되 며 1 session이 끝난 후 1 분간의 휴식시간을 제공하였으며, 1 session은 총 5 set로 이루어지며 1 set 당 분당 4-5회의 호흡운동을 시행하고 30 초의 휴식시간을 제공하였다. ${ }^{4}$

들숨성 가로막 호흡운동의 운동방법은 치료사의 손은 전방 갈비 연골 바로 아래 위치한 복직근에 올려놓은 다음 환자에게 느리고 깊 게 코로 숨을 들이마시도록 들숨성 가로막 호흡을 유도한다. 이때 치 료사는 배곧은근이 상승될 때 적절한 저항을 가하며 환자의 깊은 들 숨을 유도하며, 환자는 깊은 들숨을 하는 동안 어깨를 이완시켜 유지 하게 하고 위쪽 가슴부는 움직이지 않게 하며 복부의 상승만 허용한 다. 날숨성 입술 오므리기 호흡운동 운동방법은 환자는 깊은 들숨을 이용하여 입술을 오므리고 일정한 시간 동안 공기를 밖으로 내쉬도 록 한다(Figure 1).

\section{4. 자료분석}

자료분석 방법은 Window용 SPSS 18.0 (IBM Corporation, USA)을 이 용하여 연구대상자의 일반적 특성 및 집단의 호흡근활성도와 신체 적 기능을 Shapiro-wilk로 정규성 검정하였다. 집단 내 변화 비교는 대응표본 t-검정(Paired t-test)을 사용하였으며, 집단 간 변화 비교는 공분산분석(ANCOVA)을 사용하였고, 유의수준은 $\alpha=0.05$ 로 설정하 였다.
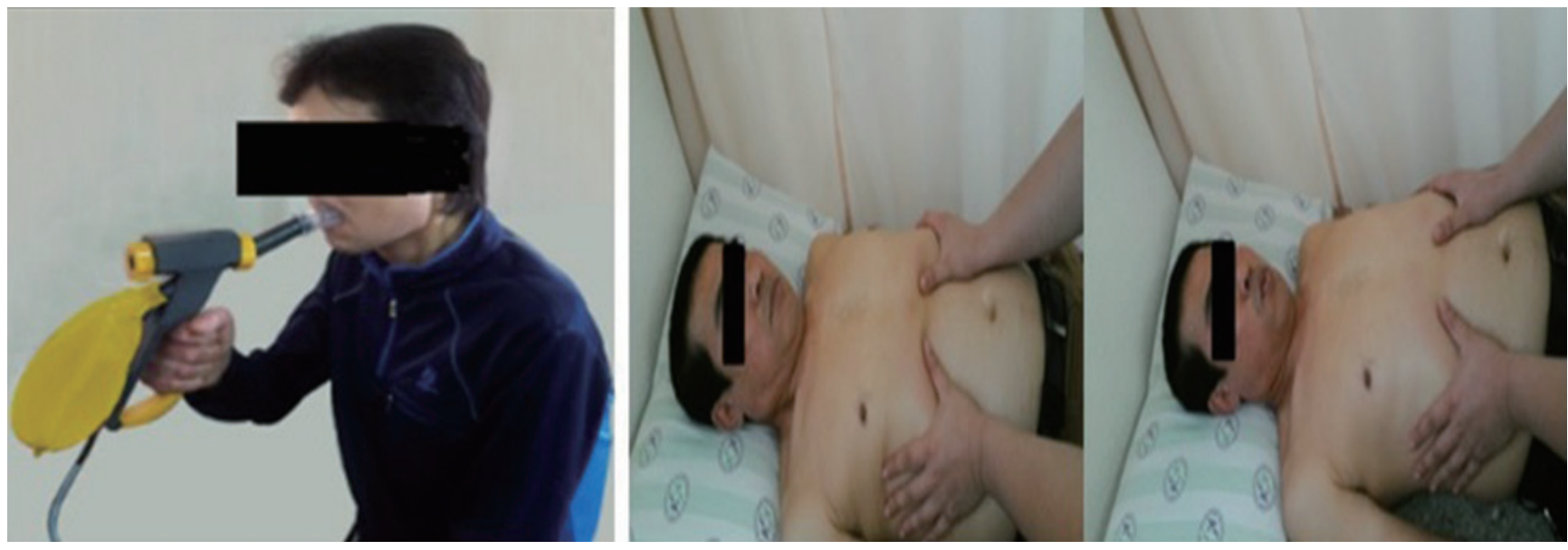

Figure 1. Feedback breathing exercise and complex exercise. 
결 과

\section{1. 연구대상자들의 일반적 특성}

실험집단 간 나이, 키, 몸무게, 체질량지수, FEV1과 FEV1/FVC에서 특 별한 변수는 없으므로 정규성을 나타내었다(Table 1).

\section{2. 실험군 의 집단 내 호흡근 활성도와 건강관련 삶의 질 변화비교}

목빗근과 목사각근에서 활성도가 유의하게 높아지는 결과를 보였다 $(\mathrm{p}<0.05)$ (Table 2).

\section{3. 실험군 I의 집단 내 호흡근 활성도와 건강관련 삶의 질 변화비교}

가로막에서만 활성도가 유의하게 높아지는 결과를 보였으며 $(\mathrm{p}<0.05)$, 건강관련 삶의 질에서도 유의한 차이가 있었다 $(\mathrm{p}<0.05)$ (Table 3).

\section{4. 실험집단 간 호흡근 활성도와 건강관련 삶의 질 변화비교}

목빗근과 목사각근의 활성도에서는 실험군 I에서 높아지는 결과를 나타내었고 $(\mathrm{p}<0.05)$, 가로막의 활성도에서는 실험군 II에서 높아지는 결과가 나타났다 $(\mathrm{p}<0.05)$. 그리고 건강관련 삶의 질에서는 실험군 II 에서 낮아지는 결과가 나타났다 $(\mathrm{p}<0.05)$ (Table 4).

\section{고 찰}

본 연구에서는 중증의 만성폐쇄성폐질환 환자에게 호흡운동을 분

Table 1. Characteristic of subjects

\begin{tabular}{lccc}
\hline & $\begin{array}{c}\text { Experimental group I } \\
(\mathrm{n}=16)\end{array}$ & $\begin{array}{c}\text { Experimental group } \\
(\mathrm{n}=15)\end{array}$ & $\mathrm{p}$ \\
& $\mathrm{M} \pm \mathrm{SD}$ & $\mathrm{M} \pm \mathrm{SD}$ & \\
\hline Age & $63.41 \pm 5.36$ & $64.02 \pm 5.15$ & 0.875 \\
hight $(\mathrm{cm})$ & $166.27 \pm 4.89$ & $167.21 \pm 4.21$ & 0.712 \\
weight $(\mathrm{kg})$ & $61.33 \pm 3.81$ & $63.12 \pm 4.91$ & 0.224 \\
BMI & $22.92 \pm 3.92$ & $23.46 \pm 3.15$ & 0.614 \\
FEV1 (\%) & $44.27 \pm 4.95$ & $42.28 \pm 6.31$ & 0.094 \\
FEV1/FVC (\%) & $42.35 \pm 3.48$ & $40.63 \pm 3.75$ & 0.078 \\
\hline
\end{tabular}

류하여 적용함으로써 호흡기능과 연관된 호흡근의 활성도와 일상생 활의 기능을 알아볼 수 있는 건강관련 삶의 질을 알아봄으로써 보다 적합한 호흡운동 방법의 효용성을 제시하고자 다음과 같은 논의를 하고자한다.

만성폐쇄성폐질환 환자는 중증도가 심화될수록 횡격막의 활동이 감소되기 때문에 보다 용이한 환기설정을 위해 불수의적인 근육을 변화시키면서 적응하게 되는데, ${ }^{16}$ Legarnd 등 ${ }^{17}$ 은 목빗근과 목갈비근 이 횡격막의 비활성화로 인한 기계적인 이득을 제공하기 위한 호흡 협력근으로써 더욱 활성화되는 특징을 가진다고 하였다. 이와 같이 호흡협력근의 변화를 연구한 선행연구들을 살펴보면 Guedes 등18은 파킨슨 병 환자에서 목빗근의 근전도 활동을 분석하기 위해 10 명의 L-Dopa 투여군과 대조군을 비교한 결과, 호흡을 하는 동안 대조군에 서 호흡협력근인 목빗근의 활성도가 보다 더 높게 나타남을 알 수 있 었으며, Gandevia 등 19 은 들숨근육들의 수축 여부를 확인하기 위해

Table 2. Comparison of change in respiratory muscle activity and quality of life within experimental group I

\begin{tabular}{|c|c|c|c|c|c|}
\hline & & \multicolumn{2}{|c|}{$\begin{array}{l}\text { Experimental group I } \\
\qquad(n=16)\end{array}$} & \multirow{2}{*}{ t } & \multirow{2}{*}{$\mathrm{p}$} \\
\hline & & $\begin{array}{l}\text { pre-test } \\
M \pm S D\end{array}$ & $\begin{array}{l}\text { post-test } \\
\mathrm{M} \pm \mathrm{SD}\end{array}$ & & \\
\hline \multirow[t]{3}{*}{$\% \mathrm{RMS}$} & SCM & $36.26 \pm 4.31$ & $42.15 \pm 4.61$ & -7.148 & $0.043^{*}$ \\
\hline & Scalenius & $49.72 \pm 5.18$ & $54.69 \pm 5.74$ & -6.451 & $0.041^{*}$ \\
\hline & Diaphragm & $31.12 \pm 1.56$ & $33.27 \pm 2.11$ & -2.208 & 0.121 \\
\hline \multicolumn{2}{|c|}{ Quality of Life } & $44.67 \pm 2.01$ & $42.92 \pm 1.19$ & -1.089 & 0.639 \\
\hline
\end{tabular}

$\star p<0.05$.

Table 3. Comparison of change in respiratory muscle activity and quality of life within experimental group ॥

\begin{tabular}{|c|c|c|c|c|c|}
\hline & & \multicolumn{2}{|c|}{$\begin{array}{l}\text { Experimental group II } \\
\qquad(n=15)\end{array}$} & \multirow{2}{*}{$\mathrm{t}$} & \multirow{2}{*}{$p$} \\
\hline & & $\begin{array}{l}\text { pre-test } \\
\mathrm{M} \pm \mathrm{SD}\end{array}$ & $\begin{array}{l}\text { post-test } \\
\mathrm{M} \pm \mathrm{SD}\end{array}$ & & \\
\hline \multirow[t]{3}{*}{$\%$ RMS } & SCM & $37.75 \pm 4.43$ & $35.41 \pm 4.81$ & 1.823 & 0.185 \\
\hline & Scalenius & $49.11 \pm 4.24$ & $47.32 \pm 4.89$ & 1.652 & 0.138 \\
\hline & Diaphragm & $33.87 \pm 2.92$ & $38.23 \pm 3.14$ & -6.481 & $0.039^{*}$ \\
\hline \multicolumn{2}{|c|}{ Quality of Life } & $43.13 \pm 1.61$ & $37.81 \pm 3.41$ & -5.833 & $0.048^{*}$ \\
\hline
\end{tabular}

Table 4. Comparison of change in respiratory muscle activity and quality of life between experimental group I and experimental group II

\begin{tabular}{|c|c|c|c|c|c|c|c|}
\hline & & \multicolumn{2}{|c|}{ Experimental group I $(n=16)$} & \multicolumn{2}{|c|}{ Experimental group $\|(n=15)$} & \multirow{2}{*}{$\mathrm{F}$} & \multirow{2}{*}{$p$} \\
\hline & & pre-test $M \pm S D$ & post-test $M \pm S D$ & pre-test $\mathrm{M} \pm \mathrm{SD}$ & post-test $M \pm S D$ & & \\
\hline \multirow[t]{3}{*}{$\%$ RMS } & SCM & $36.26 \pm 4.31$ & $42.15 \pm 4.61$ & $37.75 \pm 4.43$ & $35.41 \pm 4.81$ & 6.983 & $0.041^{*}$ \\
\hline & Scalenius & $49.72 \pm 5.18$ & $54.69 \pm 5.74$ & $49.11 \pm 4.24$ & $47.32 \pm 4.89$ & 7.747 & $0.038^{*}$ \\
\hline & Diaphragm & $31.12 \pm 1.56$ & $33.27 \pm 2.11$ & $33.87 \pm 2.92$ & $38.23 \pm 3.14$ & 5.871 & $0.047^{*}$ \\
\hline \multicolumn{2}{|c|}{ Quality of Life } & $44.67 \pm 2.01$ & $42.92 \pm 1.19$ & $43.13 \pm 1.61$ & $37.81 \pm 3.41$ & 5.879 & $0.048^{*}$ \\
\hline
\end{tabular}

$* p<0.05$. 
만성폐쇄성폐질환 환자를 대상으로 목갈비근과 갈비사이근에 단일 운동장치를 기록한 결과, 목갈비근에서 만성폐쇄성폐질환 집단에서 더욱 크게 나타났다. 그리고 Duiverman 등9은 만성폐쇄성폐질환 환 자와 10 명을 대상으로 10 분 동안 고정식 사이클을 중재 후 근활성도 를 비교한 결과, 운동을 하는 동안 만성폐쇄성폐질환 환자에서 갈비 사이근과 목갈비근의 근활성도가 크게 증가되고, 이러한 결과는 호 흡곤란으로 인한 호흡근의 역학적 이득을 증가하기 위해 꾸준히 변 화하는 현상이라고 볼 수 있으며, 본 연구에서도 실험군 I에서 목빗근 과 목갈비근에서 유의한 차이가 나타나 선행연구와 유사한 결과를 도출하였는데 피드백 호흡운동은 시각적인 요소를 더하여 들숨과 날숨을 연속적으로 연결하여 호흡운동을 하는 것으로, ${ }^{20}$ 중증 만성 폐쇄성폐질환 환자에게는 호흡훈련 장비를 이용한 중재가 협력근의 활성도를 높여 환기기능을 향상시켰다고 사료된다. 이러한 결과는 환 기시스템을 담당하는 가로막이 작용하기보다는 다른 협력근이 작용 을 증가시킴으로써 비정상적인 환기시스템이 동원되었음을 의미한 다. 그러나 이러한 비정상적인 요소들은 호흡을 유지하는 데 반드시 악영향을 미친다고는 볼 수 없는데, 그에 따른 근거로 McKenzie 등은 호흡근의 기능부전을 보상하기 위해 가로막과 더불어 목빗근과 복 부근 등의 협력근이 더 많은 움직임을 만들면 증가된 호흡용적과 각 각의 근력을 유지하는 근 섬유들의 공간이 제공됨으로 임상적으로 협력근의 동원이 중요한 의의를 지녔음을 시사하였다. 또한 Mariana 등 ${ }^{2}$ 의 연구에서도 중증의 만성폐쇄성폐질환은 기계적 역학에 의한 가슴우리의 변형으로 인해 폐의 용량감소로 호흡이 더욱 힘들어지 기 때문에 호흡 유지를 위한 호흡협력근이 폐기능 유지에 중요한 역 할을 담당하고 있는 것으로 해석하여 질환이 심화될수록 호흡협력 근의 역할은 환기유지에 중추적인 역할을 담당하는 것을 알 수 있다.

Tomich 등 22 은 가로막호흡, 기류중심, 용량중심 호흡훈련을 비교 한 결과, 기류중심 중재가 목빗근의 근활성도에 더욱 크게 향상 되어 기류중심의 깊고 느린 들숨의 중재가 목빗근의 근 활성도를 높이는 데 효과적임을 보고하였다. 그리고 Kim 등 23 은 조용한 호흡에 비해 오므린 입술호흡법은 목빗근의 활동을 억제시키고, 들숨 시 가슴우 리 확장과 1 회 호흡용적을 증가시키는 것보다 가로막의 사용빈도를 향상시킨다고 하였다. 본 연구에서도 실험군 II에서는 가로막에서만 유의한 차이가 나타났는데 그 이유로는 복합호흡운동이 오므린 입 술호흡을 기류중심의 들숨형태로 시행함으로써 목빗근의 활성도가 억제되고 또한 가로막호흡을 시행함으로써 호흡 작용근의 활성을 높여 두 중재 간의 시너지효과로 호흡 작용근의 활성도를 증가시키 는 용이한 중재방법이라고 여겨진다. 이와 같이 호흡운동 유형에 따 라 집단 간에 상이한 결과를 도출하였는데 들숨근의 활동성은 폐의 용적이나 근육의 길이에 대한 구심성 피드백에 전적으로 의존하며, 이는 하행성 신경지배와 동원 전략들에 의해 제어되어 미리 결정된
정형화된 패턴들로 생명유지에 관련된 호흡활동을 하기 위해서는 미 리 계획된 중추의 틀에서 벗어나기 힘들기 때문에, 호흡근의 보조적 인 역할 또한 중요하다고 볼 수 있다. ${ }^{24}$ 그러나 호흡보조근의 과도한 사용은 호흡작용근의 활성을 억제시키는 역학적 요소가 되기 때문 에 장기적 관점에서 보면 호흡작용근의 활성도를 높일 수 있는 중재 방법을 연구하고, 그에 따른 역학적인 요소들을 명확히 밝히기 위해 앞으로 호흡활성에 관한 많은 연구들이 필요할 것으로 사료된다.

Yamaguti 등 25 은 중증 만성폐쇄성폐질환 환자 30 명을 대상으로 가 로막호흡운동군 15 명과 호흡운동군 15 명으로 분류하여 4 주, 주 3 회, 1 일 1 회, 1 회 45 분 중재한 결과, 가로막호흡운동군이 건강관련 삶의 질에 더욱 효과적이라 하였다. 그리고 Shebl와 Fadila은 2627 명의 만성 폐쇄성폐질환 환자를 대상으로 2주, 주 3 회, 30 분 동안 복합호흡운동 을 중재하여 건강관련 삶의 질에서 유의한 차이가 나타났다. 본 연구 에서도 복합호흡운동에서만 건강관련 삶의 질에 유의한 차이가 나 타나 선행연구를 지지하고 있는데 중증의 만성폐쇄성폐질환 환자의 운동수행 능력을 감안할 때 호흡장비를 활용한 중재보다 자가호흡 기법을 활용한 중재기법이 환자의 운동수준 설정이 보다 용이하기 때문에 효율적이라는 것을 알수 있다. Puhan 등 ${ }^{27}$ 에서도 중증 만성폐 쇄성폐질환 환자에게 치료사의 훈련이 과도하여 수행할 수 없는 경 우 그 영향은 결과적으로 환자의 순응도를 크게 감소시킴으로 훈련 의 감독이 지나치게 높아도 장기적으로 볼 때에는 손해이며, 중증 만 성폐쇄성폐질환 환자에게는 자가호흡기법이 효율적이라고 하여 본 연구를 뒷받침하는 결과를 도출하였다.

중증 만성폐쇄성폐질환 환자들은 호흡유형에 따라 비교한 결과 호흡을 담당하는 가로막의 활성도는 복합호흡운동이 피드백 호흡 운동에 비하여 향상됨을 알 수 있었으며, 협력근의 활성도는 피드백 호흡운동이 복합호흡운동 보다 향상된 것으로 나타났다. 본 연구의 결과가 비록 상반되는 결과를 도출하였지만, 이는 생명유지를 위한 환기시스템에 적절히 적응하기 위한 과정으로 여겨지며, 두 중재 모 두 호흡관련 근육의 활성을 증가시키는 데 의미가 있음을 시사한다. 그러나 건강관련 삶의 질에서는 복합호흡운동이 보다 효율적인 것으 로 제시되어 중증도가 심해질수록 자가호흡기법이 환자가 적응하기 에는 용이한 것을 알 수 있었다. 이후에도 중증 만성폐쇄성폐질환 환 자들의 호흡기능 개선과 삶의 질을 높이기 위한 다각적인 접근방법 이 필요할 것으로 사료되며 지속적인 임상연구가 필요할 것이다.

본 연구의 제한점으로는 연구대상자들이 1 개의 의료기관 내에서 만성폐쇄성폐질환 환자들로 제한하였으므로 모든 만성폐쇄성폐질환 환자에 대한 일반화에 있어서는 한계가 있다는 점과, 현재 투여하고 있는 약물에 대해서도 통제하는 데 어려움이 있어 변수가 발생할 수 있다는 점, 그리고 일상생활을 통제하는 데 어려움이 있다는 점이다. 


\section{REFERENCES}

1. WHO. World Hearlth Organization.Chronic obstructive pulmonary disease (COPD). The global burden of disease: 2004 update, (2008).

2. Kim YN. Comparison of effectiveness of breathing intervention program for improvement of pulmonary functions according to prevalence period in patients with COPD. J Kor Phys Ther. 2012:24(5):355-61.

3. Loring SH, Garcia-Jacques M, Malhotra A. Pulmonary characteristics in COPD and mechanisms of increased work of breathing. J Appl Physio. 2009;107(1):309-14.

4. McKenzie DK, ButlerJE, GandeviaSC: Respiratory muscle function and activation in chronic obstructive pulmonary disease. J Appl Physiol. 2009:107(2);621-9.

5. Marquis K, Debigaré R, Lacasse Y et al. Midthigh muscle cross-sectional area is a better predictor of mortality than body mass index in patients with chronic obstructive pulmonary disease. Am J Respir Crit Care Med. 2002;166(6):809-13.

6. Ottenheijm CA, Jenniskens GJ, Geraedts MC et al. Diaphragm dysfunction in chronic obstructive pulmonary disease: A role for heparansulphate? Eur Respir J. 2007;30(1):80-9.

7. Orozco-Levi M. Structure and function of the respiratory muscles in patients with COPD: impairment or adaptation? Eur Respir J. 2003;46:41S$51 \mathrm{~S}$.

8. Kang Jl, Jeong DK, Choi H. The effect of fatigue of patients with chronic obstructive pulmonary disease on depression and the health-related quality of Life. J Kor Phys Ther. 2014;26(4):263-8.

9. Duiverman ML, Boer EW, Eykern LA et al. Respiratory muscle activity and dyspnea during exercise in chronic obstructive pulmonary disease. Respir Physiol Neurobiol. 2009;167(2):195-200.

10. Watz H, Waschki B, Meyer T et al. Physical activity in patients with COPD. Eur Respir J. 2009;33: 262-72.

11. Jones R. British thoracic society standards of care subcommittee on pulmonary rehabilitation. Thorax. 2001;56(11):827-34.

12. Moodie L, Reeve J, Elkins M. Inspiratory muscle training increases inspiratory muscle strength in patients weaning from mechanical ventilation: A systematic review. Journal of Physical Theraphy. 2011;57(4):213-21.

13. Kang Jl, Jeong DK, Park SK et al. Effects of chest resistance exercise on forced expiratory volume in one second and fatigue in patients with COPD. J Kor Phys Ther. 2011;23(2):37-43.

14. Jeong DK. The effects of breathing exercise on respiratory synergist muscle activity and $\mathrm{SpO} 2$ in patients with chronic obstructive pulmo- nary disease. J Kor Phys Ther. 2015;27(4):234-9.

15. Sartori R, Barbi E, Poli F et al. Respiratory training with a specific device in cystic fibrosis: a prospective study. J Cyst Fibros. 2008:7(4);313-9.

16. Kisner C, Colby L.A (6th ed). Therapeutic exercise: Foundations and technique. Philadelphia : FA Davis Company. 2012;993-1031.

17. Legrand A, Schneider E, Gevenois PA et al. Respiratory effects of the scalene and sternomastoid muscles in humans. J Appl Physiol. 2003;94: 1467-72.

18. Guedes LU, Parreira VF, Diório AC et al. Electromyographic activity of sternocleidomastoid muscle in patients with Parkinson's disease. J Electromyogr Kinesiol. 2009;19(4):591-7.

19. Gandevia SC, Leeper JB, McKenzie DK et al. Discharge frequencies of parasternal intercostal and scalene motor units during breathing in normal and COPD subjects. Am J Respir Crit Care Med. 1996;153:622-8.

20. Seo KC, Lee SE, , Lee JH et al. Comparison of posture on respiratory function in the stroke patients according to changes of position. J Korean soc phys med. 2011;6(4):381-9.

21. Mariana ACM, Danielle SRV, Karoline SM et al. Chest wall volumes during inspiratory loaded breathing in COPD patients. Respir Physiol Neurobiol. 2013;188:15-20.

22. Tomich GM, França DC, Diório AC et al. Breathing pattern, thoracoabdominal motion and muscular activity during three breathing exercises. Braz J Med Biol Res. 2007;40(10):1409-17.

23. Kim KS, Byun MK, Lee WH, et al. Effects of breathing maneuver and sitting posture on muscle activity in inspiratory accessory muscles in patients with chronic obstructive pulmonary disease. Multidiscip. Resp. Med. 2012;7(1):7-9.

24. Toppin VAL, Harris MB, Anna K et al. Persistence of eupnea and gasping following blockade of both serotonin type 1 and 2 receptors in the in situ juvenile rat preparation. J Appl Physiol. 2007;103(1):220-7.

25. Yamaguti WP, Claudino RC, Neto AP et al. Diaphragmatic breathing training program improves abdominal motion during natural breathing in patients with chronic obstructive pulmonary disease: A randomized controlled trial. Arch Phys Med Rehabil. 2012;93(4):571-7.

26. Shebl A, Fadila D. Impact of pulmonary rehabilitation program on health outcomes of patients with chronic obstructive pulmonary disease. J Educ Pract. 2013;4(15):78-86.

27. Puhan MA, Schünemann HJ, Buesching G et al. COPD patients' ability to follow exercise influences short-term outcomes of rehabilitation. Eur Respir J. 2008;31(2):304-10. 